Warmadewa Management and Business Journal (WMBJ)

Volume 2, Nomor 1, Februari 2020; pp. 17-25

https://ejournal.warmadewa.ac.id/index.php/wmbi

ISSN Print: 2654-816X and ISSN Online: 2654-8151

Dipublikasi: 29 Februari 2020

\title{
Analisis Efisiensi Saluran Pemasaran Bunga Hortensia Sentra Produksi Desa Gobleg Kecamatan Banjar Kabupaten Buleleng
}

\author{
Made Setena* dan Ida Ayu Sri Meitri \\ Facultas Ekonomi, Program Studi Manajemen, Universitas Warmadewa, Denpasar, Bali-Indonesia \\ Email: madesetena@gmail.com
}

\section{How to cite (in APA style):}

Setena, Made., \& Meitri, I, A, S. (2020). Analisis Efisiensi Saluran Pemasaran Bunga Hortensia Sentra Produksi Desa Gobleg Kecamatan Banjar Kabupaten Buleleng. Warmadewa Management and Business Journal 2 (1), pp. 1725

\begin{abstract}
Hortensia plants are prospective flower plants to be developed because hortensia flowers other than as ornamental plants are also used as a means of traditional ceremonies in Bali. The development of hortensia flower prices at the producer (farmer) level greatly fluctuates from the lowest price of Rp 2,000 to Rp 25,000. Hortensia flower marketing involves several marketing institutions. The research objective is to identify and analyze hortensia flower marketing channels and to find out and analyze hortensia flower marketing margins, cost sharing and profit of marketing institutions, and share prices received by farmers in each marketing channel. Data includes primary and secondary data. The number of samples is 29 farmers, with the consideration that the respondents are homogeneous and 5 are traders, 5 small traders and 15 retailers as informants. The sample uses a purposive sampling method. The results show that there are four hortensia flower marketing channel models, namely: Channel I: Farmer $\rightarrow$ Collector Trader $\rightarrow$ Small Trader $\rightarrow$ Retailer ons Consumer; Channel II: Farmers umpul Collector traders $\rightarrow$ Small traders $\rightarrow$ Consumers; Channel III: Farmer peng Collector trader $\rightarrow$ retailer ons Consumer Channel IV: Farmer peng Collector trader ons Consumer The biggest marketing margin is received by the collecting traders, which is IDR 4,250, and the smallest is received by the small traders, which is IDR 2,750. The highest marketing costs are spent by the traders, which is Rp. 1,010 per $\mathrm{kg}$ and the lowest is $R p .170$ per $\mathrm{kg}$. The profits from each marketing institution are Rp. 2,930, - collector traders, $R p$. 3,240, - small traders, Rp. 2,480, and retailers, Rp. 3,280, -. The level of marketing efficiency in each marketing institution is: farmers by $2 \%$, collecting traders $9 \%$, small traders $1 \%$ and retailers $1 \%$. The most widely used marketing channel is channel I, which is 50\% and the least marketing channel, channel IV, which is $10 \%$.
\end{abstract}

Keywords: efficiency, marketing channels

\begin{abstract}
Abstrak
Tanaman hortensia merupakan tanaman bunga yang prospektif untuk dikembangkan karena bunga hortensia selain sebagai tanaman hias juga digunakan sebagai sarana upacara adat di Bali. Perkembangan harga bunga hortensia ditingkat produsen (petani) sangat berpluktuasi mulai dari harga terndah $\mathrm{Rp} 2.000$,- sampai $\mathrm{Rp} 25.000$,-. Pemasaran bunga hortensia melibatkan beberapa lembaga pemasaran. Tujuan penelitian untuk mengetahui dan menganalsis saluran pemasaran bunga hortensia dan mengetahui dan menganalsis besarnya marjin pemasaran bunga hortensia, share biaya dan keuntungan lembaga pemasaran, serta share harga yang diterima petani pada masing-masing saluran pemasaran. Data meliputi data primer dan skunder. Jumlah sampel sebanyak 29 petani dengan pertimbangan respondennya homogim dan 5 orang pedagang pengumpul, 5 pedagang kecil dan 15 pengecer sebagai informan. Sampel menggunakan metode purposive sampling. Hasil menunjukkan ada empat model saluran pemasaran bunga hortensia, yaitu: Saluran I: Petani $\rightarrow$ Pedagang Pengumpul $\rightarrow$ Pedagang kecil $\rightarrow$ Pengecer $\rightarrow$ Konsumen; Saluran II: Petani $\rightarrow$ Pedagang pengumpul $\rightarrow$ Pedagang kecil $\rightarrow$ Konsumen; Saluran III: Petani $\rightarrow$ Pedagang pengumpul $\rightarrow$ pengecer $\rightarrow$ Konsumen Saluran IV: Petani $\rightarrow$ Pedagang pengumpul $\rightarrow$ Konsumen. Marjin pemasaran terbesar diterima oleh pedagang pengumpul yaitu sebesar Rp 4.250,- dan terkecil diterima oleh pedagang kecil yaitu sebesar Rp 2,750,. Biaya pemasaran tertinggi dikeluarka oleh pedagang pengumpul yaitu $\mathrm{Rp} 1.010$,- per $\mathrm{kg}$ dan terendah petani yaitu Rp 170,- per kg. Keuntungan yang diperoleh masing-masing lembaga pemasaran adalah petani Rp 2.930,- pedagang
\end{abstract}


pengumpul Rp 3.240,- pedagang kecil Rp 2.480,- dan pengecer Rp 3.280,-. Tingkat efisiensi pemasaran di masingmasing lembaga pemasaran yaitu: petani sebesar $2 \%$, pedagang pengumpul $9 \%$, pedagang kecil $1 \%$ dan pengecer $1 \%$. Saluran pemasaran yang paling banyak dipakai adalah saluran I yaitu sebesar 50\% dan saluran pemasaran yang paling sedikit yaitu saluran IV sebesar $10 \%$.

Kata Kunci: efisiensi, saluran pemasaran

\section{PENDAHULUAN}

Sektor pertanian dapat dijadikan basis dalam pengembangan kegiatan ekonomi pedesaan sehingga pendapatan masyarakat dapat meningkat melalui pengembangan usaha yang berbasis pertanian yaitu agrobisnis dan agroindustri. Berkembangnya perekonomian pedesaan, di samping berdampak pada pendapatan juga akan mengurangi urban ke daerah perkotaan.

Tanaman hias merupakan salah satu jenis tanaman hortikultura yang mempunyai nilai ekonomis relatif tinggi apabila diusahakan secara intensif dan komersial Tanaman ini kalau dikelola dengan baik akan mampu meningkatkan pendapatan dan kesejahteraan petani. Di samping sebagai pemenuhan hobi, tanaman hias yang berupa bunga-bungaan merupakan salah satu komoditas hortikultura cukup prospektif untuk diusahakan saat ini, karena mempunyai banyak kegunaan seperti bahan baku industri minyak wangi, pewangi kosmetik, pewangi teh, obat tradisional, bunga tabur dan bunga rangkai. Berkembangnya usahatani tanaman hias akan berdampak pada munculnya industri lainnya yang saling melengkapi seperti industri pupuk dan obat-obatan tanaman hias, pot bunga dan media tanaman hias.

Tanaman hortensia Di Bali lebih dikenal dengan nama bunga pecah seribu atau kembang seribu yang dibudidayakan sebagai bunga potong untuk pelengkap sarana upacara adat/agama terutama banten (sesaji) bagi umat Hindu yang dari-tahun ke tahun kebutuhannya meningkat seiring dengan pertambahan jumlah penduduk dan seringnya upacara keagamaan (Sumerta dkk, 2005). Bunga hortensia banyak diminati oleh masyarakat sebagai sarana upacara karena harganya yang dapat dijangkau dan bunga tersebut cukup awet bahkan dapat bertahan sampai 10 hari sejak bunga tersebut dipetik dari pohonnya. Bunga hortensia saat ini sangat mudah dijumpai di pasarpasar tradisional. Kebutuhan bunga hortensia sebagai tanaman hias dan bunga potong segar tetap diperlukan, baik dalam jangka pendek maupun jangka panjang. Konsumen bunga hortensia di Bali meliputi rumah tangga, pedagang bunga, toko-toko bunga (flower shop).

Tanaman bunga hortensia yang dibudidayakan di Desa Gobleg sekarang ini, pada mulanya hanya berupa tanaman hias untuk pekarangan, namun karena tanaman bunga hortensia dapat memberikan kontribusi dan penghasilan bagi petani bunga hortensia maka sejak tahun 1990an mulai dikembangkan. Pengembangan tanaman bunga hortensia ini juga didorong oleh keperluan masyarakat terhadap bunga hortensia cukup banyak. Tanaman bunga hortensia dapat dipanen untuk pertamakalinya setelah berumur sembilan bulan dan panen berikutnya umumnya antara 10-15 hari sekali.

Bunga hortensia yang dihasilkan oleh petani di Desa Gobleg sangat mudah dipasarkan karena setiap hari ada pembeli (pengumpul) yang datang langsung untuk membeli hasil panennya. Selanjutnya pengumpul akan memasarkan kembali ke Denpasar, Klungkung, Gianyar, Buleleng, dan Negara bahkan sampai ke Lombok. Informasi yang diperoleh dari pengumpul bahwa semua bunga yang di pasarkan laku terjual namun dengan harga yang berpluktuasi.

(Puspitasari, Ernita Dian., Asmara \& Riana, 2017) meneliti analisis efisiensi saluran pemasaran bunga mawar (studi kasus di Desa Gunung Sari, Kecamatan Bumiaji Kota Batu). Hasil penelitiannya: nilai share yang diterima petani cukup rendah jika dibandingkan dengan harga di 
tingkat konsumen. Hasil efisiensi pemasaran dengan pendekaan harga baik saluran pertama maupun kedua sudah efisien karena selisih harga lebih besar dari selisih biaya.

Pemasaran diperlukan untuk melancarkan penyebaran barang atau jasa sebagai penghubung antara manusia dengan barang atau jasa. Pemasaran bunga hortensia di Bali saat ini masih sangat terbatas, yaitu sebagian besar untuk memenuhi kebutuhan masyarakat Hindu sebagai sarana upacara agama dalam bentuk bunga potong dan sebagian kecil dibudidayakan sebagai tanaman hias untuk lansekap dan taman rumah. Sebagai tanaman yang relatif baru dibudidayakan, maka upaya pengembangannya perlu didukung dengan pola penanganan yang terarah, baik dari teknis pengolahan maupun pemasarannya, sehingga dalam jangka panjang dapat dikembangkan lebih lanjut. Perkembangan harga bunga hortensia sangat berfluktuasi dan bervariasi tergantung musim dan hari raya agama Hindu. Harga rata-rata bunga hortensia di tingkat petani berkisar antara Rp 2000,00 - Rp 25.000,00/Kg, sedangkan harga bunga hortensia di tingkat konsumen bisa mencapai $\mathrm{Rp} 8.000,00-\mathrm{Rp} 60.000,00 / \mathrm{Kg}$. Hal ini sangat tergantung atas jumlah produksi, hari raya agama, biaya pemasaran, dan keuntungan yang diinginkan oleh para pedagang. Melihat selisih harga yang cukup tinggi antara produsen di tingkat petani dengan konsumen akhir, maka peneliti tertarik untuk menganalisis Efisiensi Saluran Pemasaran Bunga Hortensia Sentra Produksi Desa Gobleg Kecamatan Banjar Kabupaten Buleleng. Adapun yang menjadi tujuan penelitian ini adalah untuk mengetahui dan menganalisis model saluran pemasaran bunga hortensia di Desa Gobleg, Kecamatan Banjar, Kabupaten Buleleng.

dan besarnya marjin pemasaran bunga hortensia, share biaya dan keuntungan lembaga pemasaran, serta sahare harga yang diterima petani pada masing-masing saluran pemasaran.

\section{TINJAUAN PUSTAKA}

(Nurbiyati, Titik. \& Machfoedz, 2005:1) Pemasaran adalah proses perencanaan dan pelaksanaan konsepsi, penetapan harga, dan distribusi ide, barang, dan jasa untuk menciptakan pertukaran yang memenuhi tujuan individu dan perusahaan. Menurut (Nitisemito, 2013:102), saluran pemasaran adalah lembaga-lembaga penyalur yang mempunyai kegiatan untuk menyalurkan/menyampaikan barang-barang/jasa-jasa dari produsen ke konsumen. Menurut (Stanton, 2015), saluran pemasaran untuk barang konsumsi terdiri atas lima saluran, yaitu

a. Produsen $\longrightarrow$ Konsumen.

B. Produsen $\rightarrow$ Pengecer $\rightarrow$ Konsumen.

C. Produsen $\rightarrow$ Pedagang Besar $\rightarrow$ Pengecer $\rightarrow$ Konsumen.

D. Produsen $\rightarrow$ Agen $\longrightarrow$ Pengecer $\longrightarrow$ Konsumen.

E. Produsen $\rightarrow$ Agen $\rightarrow$ Pedagang Besar $\rightarrow$ Pengecer $\rightarrow$ Konsumen.

Pemasaran produk pertanian berbeda dengan produk non pertanian terutama dalam konsentrasi pengumpulan produk dari petani

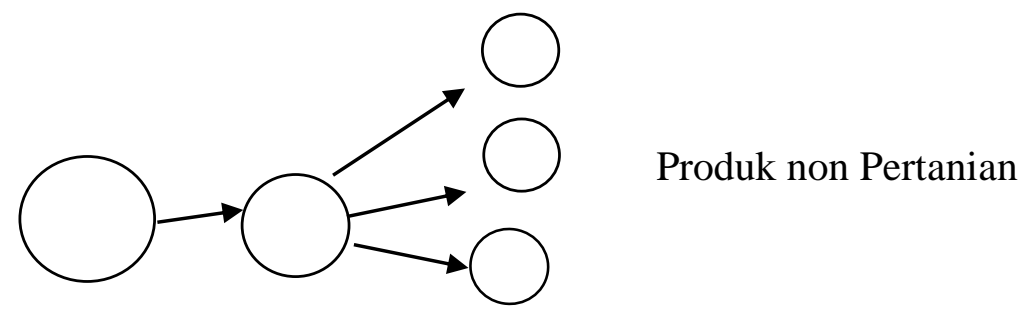




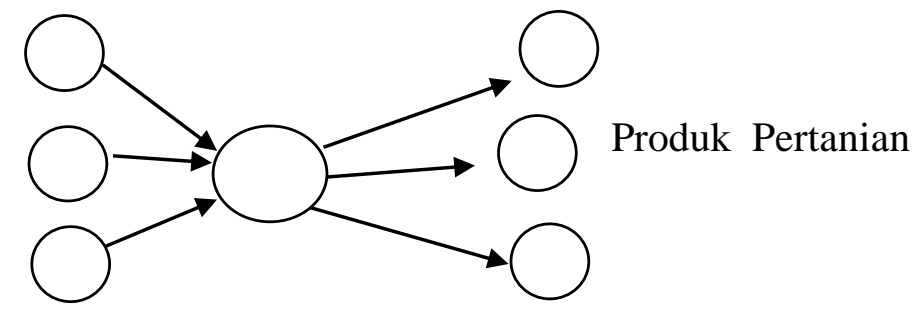

\section{III.METODE}

Metode yang digunakan dalam penelitian ini adalah deskriptif analisis yaitu prosedur pemecahan masalah yang diselidiki dengan menggambarkan keadaan subjek/objek penelitian. Pengumpulan data dengan mengadakan wawancara langsung kepada responden yang dalam hal ini adalah petani sebagai produsen bunga sebanyak 29 petani berdasarkan kuisioner yang telah disiapkan dan informan yang terdiri dari pedagang pengumpul, pedagang kecilk dan pengecer masing-masing 5 orang.

\section{HASIL DAN PEMBAHASAN}

\section{Produksi dan Panen Bunga Hortensia}

Berdasarkan hasil penelitian terhadap responden diketahui bahwa rata-rata setiap responden menggarap lahan seluas 41 are. Produksi rata-rata yang dihasilkan adalah $210 \mathrm{~kg} / \mathrm{petani}$ atau 8,8 $\mathrm{kg} /$ are dengan harga rata $\mathrm{Rp} 7.000$,-per kg. Produksi yang dihasilkan adalah dalam bentuk bunga potong. Siklus panen tanaman hortensia adalah tujuh sampai dengan 10 hari sekali. Panen/pemetikan biasanya dilakukan oleh petani sendiri atau menyewa buruh tani dengan biaya petik Rp 150,00/kg. Pemetikan bunga dilakukan dengan menggunakan gunting pemotong. Bunga dipotong pada bagian pangkal batang agar muncul cabang baru pada tempat tersebut. Setelah bunga yang dipetik dikumpulkan, tangkai bunga yang panjang dipotong lebih pendek kemudian ditempatkan pada kampil plastik dan diikat dengan tali. Agar bunga tidak layu para petani biasanya menyiram bunga dengan air dan menutupnya dengan daun pisang.

\section{Pendapatan responden}

Hasil penelitian terhadap 29 orang responden menunjukkan bahwa, pendapatan rata-rata responden per are adalah $\mathrm{Rp} 27.400,00$ setiap panen (setiap 10 hari) seperti yang disajikan pada Tabel 1

Tabel 1 Pendapatan Rata-rata responden pada Tahun 2018

\begin{tabular}{|l|l|r|}
\hline \multicolumn{1}{|c|}{ No } & \multicolumn{1}{|c|}{ Uraian } & Jumlah \\
\hline 1 & Produksi rata-rata (kg/are) & 8,80 \\
\hline 2 & Harga rata-rata (Rp/kg) & $7.000,00$ \\
\hline 3 & Penjualan (Rp/are) & $61.600,00$ \\
\hline 4 & Biaya produksi rata-rata (Rp/are) & $34.320,00$ \\
\hline 5 & Penerimaan rata-rata (Rp/are) & $27.400,00$ \\
\hline
\end{tabular}

Sumber: diolah dari data primer 


\section{Saluran Pemasaran}

Dari hasil pengamatan dan wawancara terhadap responden dilokasi penelitian maka ada empat pihak yang terlibat dalam pemasaran bunga hortensia yaitu petani sebagai produsen bunga, pedagang pengumpul, pedagang kecil, pengecer dan konsumen. Model saluran pemasaran yang dilalui oleh bunga hortensia dari produsen (petani) ke konsumen akhir ada empat model yaitu Saluran I: Petani $\rightarrow$ Pedagang Pengumpul $\rightarrow$ Pedagang kecil $\rightarrow$ pengecer $\rightarrow$ Konsumen akhir Dalam saluran ini pedagang pengumpul membeli bunga hortensia dari para petani kemudian menjualnya kepada pedagang kecil yang selanjutnya pedagang kecil menjualnya kepada pengecer dan pengecer menjual kepada konsumen akhir.

Saluran II $\quad:$ Petani $\rightarrow$ Pedagang Pengumpul $\rightarrow$ pengecer $\rightarrow$ Konsumen

Pada saluran ini petani menjual hasil pertaniannya/bunga hortensia kepada pedagang pengumpul kemudian pedagang pengumpul menyalurkan bunga hortensia kepada para pengecer yang selanjutnya menjual kepada para konsumen akhir.

Saluran III $\quad:$ Petani $\rightarrow$ Pedagang Pengumpul $\rightarrow$ Pedagang kecil $\rightarrow$ Konsumen akhir Pada saluran ini petani menjual hasil pertaniannya/bunga hortensia kepada pedagang pengumpul kemudian pedagang pengumpul menjual bunga hortensia kepada pedagang kecil dan selanjutnya menjual kepada konsumen akhir.

Saluran IV $\quad:$ Petani $\rightarrow$ Pedagang Pengumpul $\rightarrow$ Konsumen

Pada saluran ini petani menjual hasil pertaniannya/bunga hortensia kepada pedagang pengumpul untuk selanjutnya dijual kepada konsumen akhir.

Dari keempat saluran pemasaran diatas, maka dapat dibuat gambar seperti di bawah ini.

Gambar 1 Skema Saluran Pemasaran

Produsen

(Petani)

Pedagang

Pengumpul

Pedagang

Kecil

Pedagang

Pengecer

Konsumen

Akhir

Dari gambar 1 diatas terlihat bahwa saluran pemasaran bunga hortensia dari petani sampai ketangan konsumen akhir melalui saluran pemasaran yang beragam.

Biaya Pemasaran 
Biaya pemasaran berfungsi untuk membiayai komoditas selama dalam kegiatan pemasaran. Biaya yang dibutuhkan dalam kegiatan pemasaran adalah biaya yang dikeluarkan untuk memperlancar mendistribusikan barang dari tempat produsen (petani) sampai ke tempat konsumen yang meliputi biaya transportasi, karung plastik, tali rafia, biaya tenaga kerja, plasik

kecil dan retribusi. Selengkapnya data mengenai biaya pemasaran bunga hortensia pada tahun 2018 dapat dilihat pada Tabel 2 di bawah ini.

Tabel 2 Biaya pemasaran pada masing-masing lembaga pemasaran

\begin{tabular}{|l|l|l|l|}
\hline No & Lembaga Pemasaran & Jenis Biaya & Jumlah $(\mathrm{Rp} / \mathrm{Kg})$ \\
\hline 1 & Petani & ongkos petik & 150 \\
\hline & & tali plastik & 20 \\
\hline 2 & Total & & 170 \\
\hline & Pedagang Pengumpul & & \\
\hline & & Retribusi & 50 \\
\hline & & tenaga kerja & 400 \\
\hline & & transportasi & 500 \\
\hline & & tali plastik & 20 \\
\hline & Total & karung plastik & 40 \\
\hline 3 & Pedagang Kecil & Retribusi & 1010 \\
\hline & & tenaga kerja & 150 \\
\hline & & transportasi & 100 \\
\hline & Total & & 270 \\
\hline 4 & Pengecer & Retribusi & 20 \\
\hline & & Transportasi & 100 \\
\hline & & Kresek kecil & 100 \\
\hline & Total & & 220 \\
\hline
\end{tabular}

Sumber: diolah dari data primer

Pada Tabel 2 diatas dapat dilihat bahwa pedagang pengumpul mengeluarkan biaya pemasaran tertinggi yaitu sebesar Rp 1.010,- per kg dan terkeci ada pada petani dengan jumlah Rp 170 ,- per kg. Komponen biaya yang terbesar ada pada biaya transportasi hal ini disebabkan karena jaraknya cukup jauh dari produsen ke tempat pemasaran.

\section{Analisis Marjin Pemasaran}

Marjin pemasaran merupakan selisih antara harga jual dengan harga beli pada masingmasing lembaga pemasaran. Besarnya marjin pemasaran dapat dilihat pada tabel 3 di bawah ini. 
Tabel 3 Marjin Pemasaran pada Masing-masing Lembaga Pemasaran

\begin{tabular}{|r|l|r|r|r|r|}
\hline No & Lembaga Pemasaran & $\begin{array}{l}\text { Harga } \\
\text { Beli } \\
(\mathrm{Rp} / \mathrm{Kg})\end{array}$ & $\begin{array}{l}\text { Harga } \\
\text { Jual } \\
(\mathrm{Rp} / \mathrm{Kg})\end{array}$ & $\begin{array}{l}\text { Marjin } \\
(\mathrm{Rp} / \mathrm{Kg})\end{array}$ \\
\hline 1 & Petani & 3900 & 7000 & 3100 \\
\hline 2 & Pedagang Pengumpul & 7000 & 11250 & 4250 \\
\hline 3 & Pedagang Kecil & 11250 & 14000 & 2750 \\
\hline 4 & Pengecer & 14000 & 17500 & 3500 \\
\hline
\end{tabular}

Sumber : diolah dari data primer

Tabel 3 diatas menunjukkan bahwa marjin terbesar diterima oleh pedagang pengumpul yaitu sebesar Rp 4.250,- per kg dan marjin terkecil diterima oleh pedagang kecil sebesar 2.750,-Sedangkan marjin pemasaran sebesar Rp 10.500,- yang merupakan perbedaan harga ditingkat petani dengan harga pedagang pengecer. Besarnya marjin ini disebabkan panjangnya jalur yang dilalui dari petani sampai ketangan konsumen akhir.

\section{Analisis Keuntungan dan Efisiensi Pemasaran}

Untuk dapat menganalisis keuntungan pemasaran bunga hortensia pada masing-masing lembaga pemasaran maka diperlukan data harga jual, harga beli dan biaya pemasaran. Perhitungan keuntungan pada masing-masing lembaga pemasaran terlihat seperti tabel dibawah ini.

Tabel 4 Keuntungan pada masing-masing lembaga Pemasaran

\begin{tabular}{|r|l|r|r|r|r|}
\hline No & $\begin{array}{l}\text { Lembaga } \\
\text { Pemasaran }\end{array}$ & $\begin{array}{l}\text { Harga } \\
\text { Beli } \\
(\mathrm{Rp} / \mathrm{Kg})\end{array}$ & $\begin{array}{l}\text { Harga } \\
\text { Jual } \\
(\mathrm{Rp} / \mathrm{Kg})\end{array}$ & $\begin{array}{l}\text { Biaya } \\
(\mathrm{Rp} / \mathrm{Kg})\end{array}$ & $\begin{array}{l}\text { Keuntungan } \\
(\mathrm{Rp} / \mathrm{Kg})\end{array}$ \\
\hline 1 & Petani & 3900 & 7000 & 170 & 2930 \\
\hline 2 & $\begin{array}{l}\text { Pedagang } \\
\text { Pengumpul }\end{array}$ & 7000 & 11250 & 1010 & 3240 \\
\hline 3 & Pedagang Kecil & 11250 & 14000 & 270 & 2480 \\
\hline 4 & Pengecer & 14000 & 17500 & 220 & 3280 \\
\hline
\end{tabular}

Sumber: diolah dari data primer

Perbedaan harga pada masing-masing lembaga pemasaran disebabkan karena adanya tambahan biaya-biaya yang dikeluarkan pada lembaga pemasran tersebut. Dari tabel 5.9 diatas terlihat bahwa keuntungan tertinggi ada pada pengecer yaitu sebesar Rp 3.280,-per kg dan terendah diterima oleh pedagang kecil sebesar Rp 2.480,-per kg.

Analisis Efisiensi pemasaran

Efisiensi biaya pemasaran merupakan perbandingan antara biaya pemasaran dengan nilai penjualan produk. Semakin kecil hasil perhitungannya akan semakin baik. Hasil perhitungan efisiensi biaya pemasaran masing-masing lembaga pemasaran dapat dilihat pada tabel 5. di bawah ini: 
Tabel 5 efisiensi pemasaran di masing-masing lembaga pemasaran

\begin{tabular}{|r|l|r|l|l|}
\hline No & Lembaga Pemasaran & $\begin{array}{l}\text { Biaya } \\
\text { pemasaran } \\
(\mathrm{Rp} / \mathrm{Kg})\end{array}$ & $\begin{array}{l}\text { Harga } \\
\text { Jual } \\
(\mathrm{Rp} / \mathrm{Kg})\end{array}$ & $\begin{array}{l}\text { nilai efisiensi } \\
(\mathrm{Rp} / \mathrm{Kg})\end{array}$ \\
\hline 1 & Petani & 170 & 7000 & 0,02 \\
\hline 2 & Pedagang Pengumpul & 270 & 11250 & 0,09 \\
\hline 3 & Pedagang Kecil & 220 & 17000 & 0,02 \\
\hline 4 & Pengecer & & 0,01 \\
\hline
\end{tabular}

Sumber: diolah dari data primer

Dari tabel 5 diatas terlihat bahwa nilai efisiensi paling baik ada pada pengecer. Hal ini disebabkan karena biaya pemasaran yang dikeluarkan cukup kecil dibandingkan dengan harga jualnya.

\section{Analisis Saluran Pemasaran}

Untuk mengetahui share harga, biaya pemasaran, keuntungan, marjin dan nilai efisiensi pada masing-masing saluran pemasaran, maka di bawah ini akan disajikan dalam bentuk tabel dari hasil perhitungan sebelumnya.

Tabel 6 Analisis Saluran Pemasaran

\begin{tabular}{|c|c|c|c|c|c|c|c|}
\hline No & $\begin{array}{l}\text { Lembaga } \\
\text { Pemasaran }\end{array}$ & $\begin{array}{l}\text { Harga } \\
\text { Beli } \\
\text { (Rp/Kg) }\end{array}$ & $\begin{array}{l}\text { Harga } \\
\text { Jual } \\
(\mathrm{Rp} / \mathrm{Kg})\end{array}$ & $\begin{array}{l}\text { Biaya } \\
(\mathrm{Rp} / \mathrm{Kg})\end{array}$ & $\begin{array}{l}\text { Keuntungan } \\
(\mathrm{Rp} / \mathrm{Kg})\end{array}$ & $\begin{array}{l}\text { Marjin } \\
(\mathrm{Rp} / \mathrm{Kg})\end{array}$ & $\begin{array}{l}\text { Nilai } \\
\text { Efisiensi } \\
(\mathrm{Rp} / \mathrm{Kg})\end{array}$ \\
\hline \multicolumn{8}{|c|}{ Model Saluran Pertama } \\
\hline 1 & Petani & 3900 & 7000 & 170 & 2930 & 3100 & 0,02 \\
\hline 2 & $\begin{array}{l}\text { Pedagang } \\
\text { Pengumpul }\end{array}$ & 7000 & 11250 & 1010 & 3240 & 4250 & 0,09 \\
\hline 3 & $\begin{array}{l}\text { Pedagang } \\
\text { Kecil }\end{array}$ & 11250 & 14000 & 270 & 2480 & 2750 & 0,02 \\
\hline 4 & Pengecer & 14000 & 17500 & 220 & 3280 & 3500 & 0,01 \\
\hline \multicolumn{8}{|c|}{ Model Saluran Kedua } \\
\hline 1 & Petani & 3900 & 7000 & 170 & 2930 & 3100 & 0,02 \\
\hline 2 & $\begin{array}{l}\text { Pedagang } \\
\text { Pengumpul }\end{array}$ & 7000 & 11250 & 1010 & 3240 & 4250 & 0,09 \\
\hline 4 & Pengecer & 14000 & 17500 & 220 & 3280 & 3500 & 0,01 \\
\hline \multicolumn{8}{|c|}{ Model Saluran Ketiga } \\
\hline 1 & Petani & 3900 & 7000 & 170 & 2930 & 3100 & 0,02 \\
\hline 2 & $\begin{array}{l}\text { Pedagang } \\
\text { Pengumpul }\end{array}$ & 7000 & 11250 & 1010 & 3240 & 4250 & 0,09 \\
\hline 4 & $\begin{array}{l}\text { Pedagang } \\
\text { Kecil }\end{array}$ & 11250 & 14000 & 270 & 2480 & 2750 & 0,02 \\
\hline
\end{tabular}




\begin{tabular}{|r|l|r|r|r|r|r|r|}
\hline \multicolumn{7}{|c|}{ Model Saluran Keempat } \\
\hline 1 & Petani & 3900 & 7000 & 170 & 2930 & 3100 & 0,02 \\
\hline 2 & $\begin{array}{l}\text { Pedagang } \\
\text { Pengumpul }\end{array}$ & 7000 & 11250 & 1010 & 3240 & 4250 & 0,09 \\
\hline
\end{tabular}

Berdasarkan tabel 6 diatas dapat disimpulkan bahwa saluran pemasaran yang efisien adalah saluran yang mengeluarkan biaya kecil, marjinya besar dan saluran yang dilalui pendek. Jadi model saluran pemasaran yang paling efisien adalah saluran yang keempat dengan biaya yang paling kecil, marjin besar dan saluran paling pendek. Namun demikian saluran pemasaran model keempat (IV) ini paling sedikit digunakan oleh lembaga pemasaran karena keterbatasan dalam menyalurkan produknya. Dari pengamatan dan wawancara terhadap informan hanya $1 \%$ yang menggunakan saluran model keempat ini dan yang terbanyak digunakan adalah saluran pemasaran model satu (I).

\section{KESIMPULAN}

1. Model saluran pemasaran yang dipakai untuk menyalurkan bunga hortensia dari petani sampai ketangan konsumen akhir ada empat yaitu: Saluran I: Petani $\rightarrow$ Pedagang Pengumpul $\rightarrow$ Pedagang kecil $\rightarrow$ Pengecer $\rightarrow$ Konsumen; Saluran II: Petani $\rightarrow$ Pedagang pengumpul $\rightarrow$ Pedagang kecil $\rightarrow$ Konsumen; Saluran III: Petani $\rightarrow$ Pedagang pengumpul $\rightarrow$ pengecer $\rightarrow$ Konsumen Saluran IV: Petani $\rightarrow$ Pedagang pengumpul $\rightarrow$ Konsumen.

2. Marjin pemasaran kalau dilihat dari harga ditingkat petani dengan harga pengecer cukup besar yaitu sebesar Rp 10.500,-. Marjin pemasaran tersebut terbesar diterima oleh pedagang pengumpul yaitu sebesar $\mathrm{Rp} 4.250$,- dan terkecil diterima oleh pedagang kecil yaitu sebesar Rp 2,750,- sisanya sebesar Rp 3.500,- oleh pengecer.

3. Keuntungan terbesar dinikmati oleh pedagang pengecer yaitu sebesar Rp 3.280,- per kg dan biaya pemasaran tertinggi dikeluarkan oleh pedagang pengumpul yaitu sebesar Rp $1.010,-$ per kg.

4. Saluran pemasaran yang paling banyak dipakai adalah saluran model satu (I) yaitu 50\% dan yang paling sedikit dipakai saluran model empat (IV) yaitu $10 \%$.

\section{DAFTAR PUSTAKA}

Nitisemito, A. S. (2013). Marketing. Ghalia Indonesia.

Nurbiyati, Titik., \& Machfoedz, M. (2005). Manajemen Pemasaran Kontemporer. Kayon.

Puspitasari, Ernita Dian., Asmara, R., \& Riana, F. D. (2017). Analisis Efisiensi Pemasaran Bunga Mawar Potong (Studi Kasus Di Desa Gunungsari, Kecamatan Bumiaji, Kota Batu). Jurnal Ekonomi Pertanian Dan Agribisnis (JEPA)., 1(2).

Stanton, W. J. (2015). Prinsip Pemasaran (7th ed.). Erlangga. 